\section{EMBRYARIDDLE}

Aeronautical University

SCHOLARLY COMMONS
Journal of Aviation/Aerospace

Education \& Research

Volume 12

Number 3 JAAER Spring 2003

Article 1

Spring 2003

\title{
A Evaluation of the Perceived Effect of Personal Computer Aviation Training Devices for Instrument Flight Training
}

Wendy Beckman

Follow this and additional works at: https://commons.erau.edu/jaaer

\section{Scholarly Commons Citation}

Beckman, W. (2003). A Evaluation of the Perceived Effect of Personal Computer Aviation Training Devices for Instrument Flight Training. Journal of Aviation/Aerospace Education \& Research, 12(3).

https://doi.org/10.15394/jaaer.2003.1568

This Article is brought to you for free and open access by the Journals at Scholarly Commons. It has been accepted for inclusion in Journal of Aviation/Aerospace Education \& Research by an authorized administrator of Scholarly Commons. For more information, please contact commons@erau.edu. 


\title{
A EVALUATTON OF THE PERCEIVED EFFECTIVENESS OF PERSONAL COMPUTER AVATION TRAINING DEVICES FOR INSTRUMENT FLIGHT TRAINING
}

\author{
Wendy Beckman
}

\begin{abstract}
As personal computer aviation training devices (PCATDs) come into wider use for instrument flight training, the question of the effectiveness of these devices continues to be asked. This paper reports the findings of a survey designed to measure the perceived effectiveness of PCATDs for various lessons in instrument flight training. Flight students and flight instructors who utilized PCATDs for 12 specific flight lessons were administered a Likert-scale questionnaire which requested an effectiveness rating for each lesson. The perceived effectiveness of PCATDs for use in assignments outside the curriculum was also investigated. The PCATDs were rated to be most effective in the flight lessons that introduced a new concept, versus lessons that reviewed a concept already known. The devices were rated as very effective for additional student practice beyond the curriculum.
\end{abstract}

\section{INTRODUCTION}

Ground training devices have long been used to teach students basic instrument flight skills. The device which has been most commonly used in the last several decades is a flight training device (FTD). Although there are seven levels of FTDs, such devices generally replicate an aircraft cockpit and often have a basic visual display system. FTDs are currently used for instrument training in the majority of leading university flight training programs, as well as at smaller flight schools nationwide.

A new type of ground training device, the personal computer aviation training device (PCATD) has become available to flight students and their instructors in the last decade. These devices typically consist of a generic aircraft control console which provides the flight controls necessary for performing flight maneuvers, as well as a visual display on a PC monitor, consisting of the flight instruments seen in an aircraft. PCATDs are typically Microsoft Windows driven on a $P C$ platform. The FAA recognized PCATDs as a viable method of obtaining instrument flight training beginning in 1997, by allowing ten hours of PCATD training to substitute for aircraft flight time in training for an instrument rating (FAA, 1997). This decision caused controversy within the industry, as at that time there had been little research into the effectiveness of PCATD training.
Since PCATDs offer a much lower cost alternative to ground-based flight training than FTDs, there continues to be much interest in the viability of these trainers. There have now been several studies investigating the transfer effectiveness of learning from PCATDs to both FTDs and to actual aircraft. These studies are discussed in detail in the Review of Relevant Literature section of this article. However, there appears to have been no studies to date concerning the perceived effectiveness of PCATDs by the students and instructors who have utilized these devices in instrument training. At Parks College of Engineering and Aviation of Saint Louis University, PCATDs have been used as a part of the College's FAA Part 141 instrument flight training curriculum since the fall of 1997. This study attempts to analyze the perceived effectiveness of these devices for conducting such training from both the flight student and flight instructor point of view.

\section{STATEMENT OF THE PROBLEM}

The purpose of this study was to gather data regarding the experiences of Parks College instrument students and flight instructors in using the Colleges' PCATDs. The specific research question investigated was: "Do Parks College flight students and instructors perceive PCATDs to be an effective instrument training device?" Two very similar Likert-scale questionnaires were developed for use in this study. One questionnaire was used 
for the collection of flight student opinions, and other for the collection of flight instructor opinions. Each question in the survey addressed the effectiveness perceived for a specific flight lesson conducted in a PCATD, of which there was a total of twelve. In addition, the survey included several questions regarding whether the PCATDs were used for assignments outside of the curriculum and their perceived effectiveness when used in this manner. A comment area was also provided for statements any participant desired to make regarding the use of the PCATDs in the curriculum.

\section{Review of Relevant Literature}

There have been several studies which evaluated the effectiveness of PCATDs by measuring transfer of learning to either a FTD or an aircraft. Oritz (1993) conducted a study which used a PCATD to provide initial training in visual flight maneuvers for student pilots. This study found there was a positive transfer of learning from the PCATD to an aircraft. Another study regarding the effectiveness of PCATDs was conducted at the University of Illinois during the 1994-1995 academic year (Taylor, Lintern, Hulin, Talleur, Emanuel, Phillips, 1997). This study evaluated a PCATD in a transfer of training experiment to evaluate its ability to assist in instrument flight training. The researchers found that the level of savings in airplane flight time varied from negative $25 \%$ to positive $40 \%$, depending on the particular tasks involved. However, generally speaking, the transfer savings were positive, particularly when new maneuvers were being introduced.

A study conducted by Homan and Williams (1997) at Arizona State University compared the effectiveness of PCATDs versus FTDs in preparing instrument flight students to perform distance measuring equipment (DME) arcs. In this study, the researchers found that practice in either the PCATDs or the FTDs used in the study resulted in improved overall performance in performing DME arcs. The PCATDs were found to be as effective as the FTDs in the parameter of maintaining appropriate distance on the DME arc. However, the PCATDs were not as effective as the FTDs in improving altitude control. In an earlier study conducted at Parks College (Beckman, 2000) the comparative effectiveness of PCATDs and FTDs in preparing students for the specific instrument flight training skill of holding patterns was evaluated. It was found that PCATDs and FTDs were equally effective in preparing instrument flight students to perform holding patterns in a TB-9 aircraft.

In summary, there have been several studies which have evaluated the effectiveness of PCATDs. Each of the above mentioned studies attempted to provide a sense of the amount of transfer of learning that occurred from a PCATD to either a FTD or an aircraft. The findings have been varied, with PCATDs appearing to be effective in some areas of flight training, and perhaps not as effective in others.

To date, there has been no published research regarding the views of the users of PCATD's. Since flight students and instructors have now been using these devices for several years, their ideas and perceptions regarding the usefulness of these devices may be of interest to the educational community. While some readers may contend that descriptive research is not as "scientific" as would be desired, survey methodology has a long history in educational research. Borg and Gall (1989) state, "Studies involving surveys account for a substantial proportion of the research done in the field of education... a wide range of educational problems can be investigated in survey research". Likewise, Gay (1992) concludes that "the descriptive method is useful for investigating a variety of educational problems". Thus, this study attempts to add to the overall picture that is developing regarding the effectiveness of PCTAD usage through surveying the users of the devices.

\section{METHODOLOGY}

\section{Subjects}

The study population consisted of those students in the Parks College Part 141 training program who were enrolled in Aeroscience III (Commercial ground school) during the Fall 2000 and Spring 2001 semesters, and the flight instructors on staff at Parks College during the Spring 2001 semester. Fifty-seven instrument flight students and twelve flight instructors participated in the study. Each surveyed student had utilized the Colleges' Jeppesen FS-200 PCATDs for twelve lessons in their instrument training curriculum. This specific PCATD represents a high performance single-engine aircraft, and consists of a flight console displayed on a 20 inch monitor. The system is driven by an IBM compatible Pentium, $100 \mathrm{MHz}$ personal computer. A pilot yoke and rudder controls are also part of the PCATD system.

Each surveyed student had completed their 
instrument graduation checkride. This was to insure that each participant had not only completed the PCATD component of the curriculum, but the FTD component and the aircraft component as well. This was important, since a student in the midst of instrument flight training would not likely have as accurate a perception regarding the effectiveness of various components of their training as a student who had completed the training in its entirety and could reflect on the entire experience. Flight instructor participants in the survey had instructed at least one student through the entire Parks College instrument curriculum. Again, the ability to reflect on the entirety of the instrument training curriculum, along with the part the PCATD's played in that training, was considered critical to obtaining the most informed response possible.

Student response rate was excellent (100\%), since the survey was completed during their required Commercial ground school class. However, only slightly more than half $(57 \%)$ of the flight instructor staff who were qualified to do so chose to respond to the survey.
Instrument

Each subject completed a Likert-style questionnaire regarding perceived effectiveness of the PCATDs for each lesson conducted in the device. As mentioned previously, in the Parks College instrument training curriculum, there are a total of twelve PCATD lessons. Four PCATD lessons imvolve basic attitude instrument flight, five PCATD lessons involve instrument navigation, and three PCATD lessons involve instrument approaches. In Table 1 a listing of the twelve questions regarding lesson effectiveness can be seen. On the questionnaire, students and instructors were able to indicate the level of perceived effectiveness on a scale from 1 (very effective) to 5 (very ineffective). To assist in their memory of the lessons, each respondent was given the opportunity to refer back to the specific lesson page in the flight curriculum, where more detail regarding the specific content and requirements of each lesson was provided.

Table 1

\begin{tabular}{|l|}
\hline \multicolumn{1}{|c|}{ Questions Regarding Effectiveness of PCATDs in Curriculum } \\
\hline 1. Lesson 51 - Introduction to basic attitude instrument flight \\
\hline 2. Lesson 52 - Continued introduction to basic attitude instrument flight \\
\hline Lesson 55 - Introduction to partial panel flight \\
\hline 4. Lesson 56 - Continued partial panel flight; Unusual attitudes; Introduction to magnetic compass turns \\
\hline $\begin{array}{l}\text { 5. Lesson } 62 \text { - Review VOR orientation/navigation; Introduction to simple holding patterns (no wind, direct } \\
\text { entry) }\end{array}$ \\
\hline Lesson 63 - Review NDB orientation/navigation; Practice simple holding patterns \\
\hline Lesson 66 - Introduction to Holding Pattern Entries \\
\hline Lesson 67 - Continued Holding Pattern Entries \& Holding Patterns \\
\hline 9. Lesson 68 - Continued Holding Patterns (wind correction) \\
\hline 10. Lesson 78 - Introduction to VOR approaches \\
\hline 11. Lesson 79 - Introduction to NDB approaches \\
\hline 12. Lesson 82 - Introduction to Precision and LOC BC approaches \\
\hline
\end{tabular}


In addition to the Questions seen in Table 1, the use of the PCATDs for additional reinforcement outside the curriculum was explored. Each student was asked to indicate whether their instructor had assigned homework in the PCATDs, and if they had, what that assignment had been. They were also asked to indicate the perceived effectiveness of the assignments they received. Another series of questions probed whether students had ever taken the initiative to practice in the PCATDs of their own accord. If they had, they were again asked what they had worked on, and how effective they perceived that experience to have been.

Flight instructor participants were asked if they had ever assigned homework in the PCATDs, of what those assignments consisted, and how effective they thought the
PCATDs had been for accomplishing that homework. Instructors were also asked to indicate if any of their students had practiced on their own, and how effective that practice had been. Finally, space was provided for qualitative comments regarding PCATD effectiveness if the respondent desired to provide such.

\section{Perceived Effectiveness of PCATDs in an Instrument Training Curriculum \\ Results}

The results of the student and instructor PCATD surveys regarding the effectiveness of PCATDs as a part of the instrument training curriculum can be seen in Table 2 . 


\section{TABLE 2}

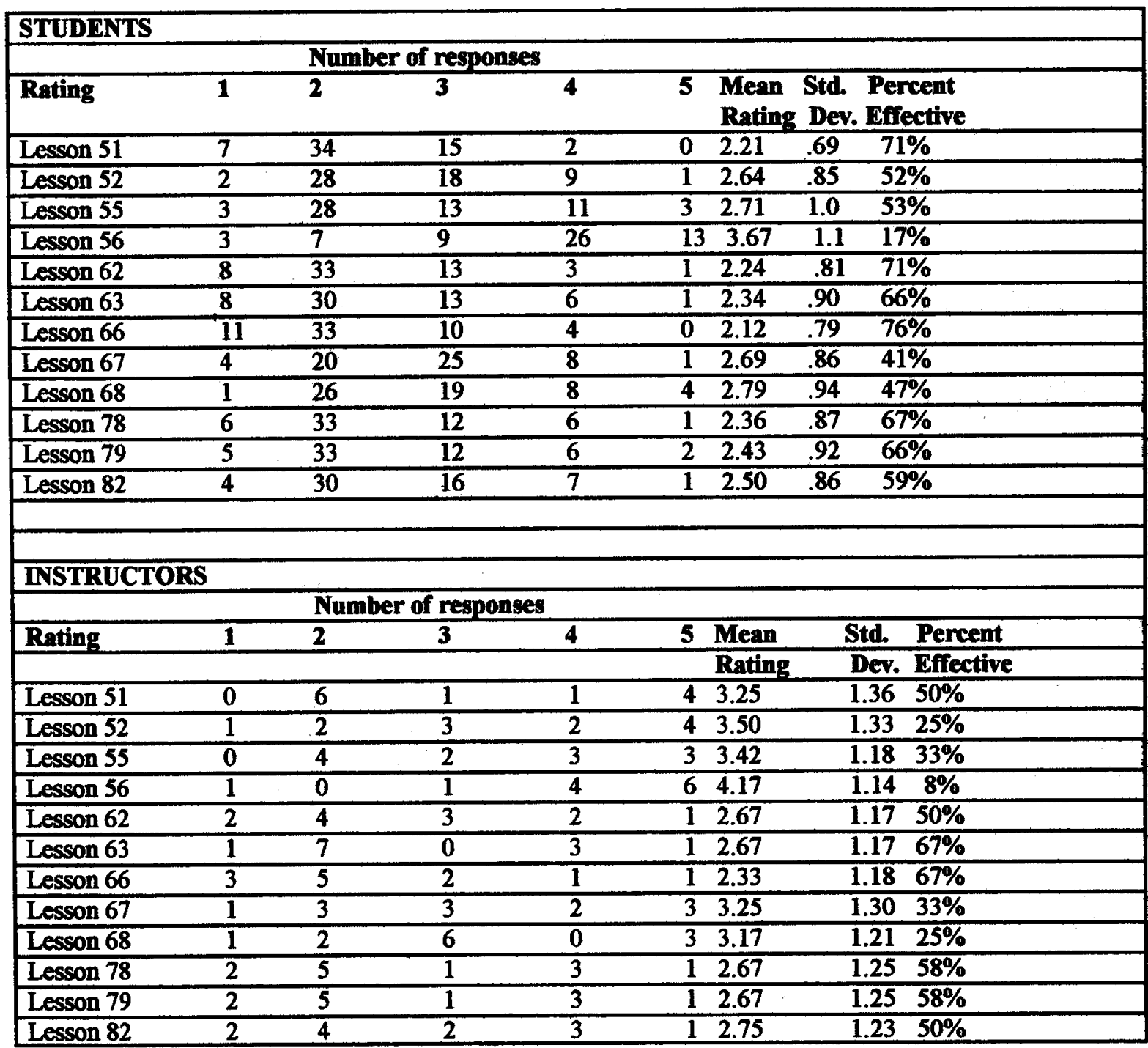

Rating Legend:

$1=$ Very effective

2=Effective

$3=$ Neutral

4=Ineffective

$5=$ Very ineffective 
The data seen in the "Number of Responses in Each Category" section of this Table indicates the number of times each response was indicated. The "Mean Rating" column indicates the mean response of the participants, the "Std. Dev." Column indicates the standard deviation of the reponses, and the "Percent Effective" column indicates the percentage of participants that rated the lesson as either "very effective" or "effective". The student participants indicated that each lesson, with the exception of Lesson 56, was better than neutral (rating mean less than 3.0 ) in terms of effectiveness. The flight instructor participants indicated that six of the twelve lessons were better than neutral in terms of effectiveness. The mean effectiveness of all the lessons was 2.56 for students and 3.04 for instructors.

\section{Discussion}

The lessons students indicated as most effective included Lessons $51,62,63,66,78,79$, and 82 . The lessons that instructors rated most effective included
Lessons $62,63,66,78,79$, and 82 . With the exception of Lesson 51, it is interesting to note that identical lessons were indicated as effective by both instructors and students. The common denominator for each of the lessons that were indicated "effective" is that they were each an introductory lesson to a new skill. In contrast, Lessons 67 and 68, which provided continued practice in holding patterns and holding pattern entries, were not seen as effective by instructors. Although students did find these lessons effective, they were not ranked as highly as the lessons which introduced new concepts.

If the lessons are grouped by type, Lesson 51,52 , 55, and 56 are Basic Attitude Instrument lessons. Lesson 62, 63, and 66 are Introduction to Holding Pattern lessons, Lessons 67 and 68 are Continued Holding Pattern lessons, and Lessons 78, 79, and 82 are Introduction to Approach lessons. The mean effectiveness rated by both instructors and students for these groupings can be seen in Table 3.

Table 3

\begin{tabular}{|llll|}
\hline & & \multicolumn{2}{c|}{ Mean Effectiveness } \\
& & Rating & Student \\
Lessons 51,52,55,56 & Basic Attitude Instrument & 2.81 & 3.59 \\
Lessons 62,63,66 & Holding Pattern Introduction & 2.23 & 2.56 \\
Lessons 67,68 & Holding Pattern Practice & 2.74 & 3.21 \\
\hline
\end{tabular}

It is interesting to note that both instructors and students ranked the groupings in the following order (from most effective to least effective) - Holding Pattern introduction, Approach introduction, Holding pattern Contimued Practice, and Basic Attitude Instrument lessons. This analysis also supports the conclusion that both instructors and students find introductory lessons to be most beneficial in PCATDs, while later lessons on a given topic are more effectively handled in an FTD or airplane. This finding is consistent with the research of Taylor, et. al. (1997) at the University of Illinois, which indicated that lesser fidelity devices are appropriate for early stages of learning, with higher fidelity devices required for later stages.

It is interesting to note that the BAI lessons are not as highly regarded as effective as other "introductory" lessons. Perhaps the reason for this is that students are exposed to BAl training, albeit in a limited fashion, during their Private Pilot training, so the concept is not truly "new" when introduced in Instrument training.

The universal ranking of Lesson 56 as ineffective by both students and instructors was found to have a simple explanation. This lesson included a large segment of practice time involving magnetic compass turns. Unfortunately, the Jeppesen FS-200 PCATDs do not accurately simulate the magnetic dip errors of a magnetic compass. The "magnetic compass" indicator in these PCATDs functions like a heading indicator, and so students were unable to experience the difficulties of actual magnetic compass turns. This problem is one specific to this particular software, and should readily be able to be overcome. 


\section{Perceived Effectiveness of PCATDs for Homework Assignments \\ Results}

The results of the responses to the questions regarding homework can be seen in Table 4. Thirty-nine percent of the students surveyed indicated that their instructors had assigned homework in the PCATDs. Of those who said they were assigned homework, a mean effectiveness of 2.8 was indicated. Sixty-seven percent of the students surveyed indicated that they had practiced on their own in the PCATDs (without a specific assignment from their instructor), and indicated a mean effectiveness of 2.57 for these practice sessions.

Every instructor who completed the survey indicated that they assigned homework in the PCATDs to their students, and indicated a mean effectiveness of 2.18 for these assignments (see Table 4).

Table 4

\begin{tabular}{|c|c|c|c|}
\hline \multicolumn{4}{|l|}{ STUDENTS } \\
\hline & Yes & No & Percent Assigned Homework \\
\hline Assigned Homework? & 22 & 35 & $39 \%$ \\
\hline$c^{2}$ & & & \\
\hline \multicolumn{4}{|c|}{ Mean Effectiveness Indicated $=\mathbf{2 . 8}$} \\
\hline & Yes & No & Percent That Practiced \\
\hline Practiced on Own? & 29 & 14 & $67 \%$ \\
\hline \multicolumn{4}{|c|}{ Mean Effectiveness Indicated $=2.57$} \\
\hline \multicolumn{4}{|l|}{ INSTRUCTORS } \\
\hline & Yes & No & Percent Assigned Homework \\
\hline Assigned Homework? & 12 & $\mathbf{0}$ & $100 \%$ \\
\hline \multicolumn{4}{|c|}{ Mean Effectiveness Indicated $=\mathbf{2 . 1 8}$} \\
\hline & Yes & No & Percent Whose Students Practiced \\
\hline Practiced on Own? & 4 & 8 & $33 \%$ \\
\hline
\end{tabular}

Only $33 \%$ of the instructors surveyed indicated that their students used the PCATDs on their own. However, of the four instructors which did indicate their students practiced on their own, a mean effectiveness of 1.25 was indicated.

\section{Discussion}

It seems likely that many times students have not communicated to their instructors when they practice on their own in a PCATD, and also likely that there is miscommunication regarding instructor assignments (since $100 \%$ of participating instructors reported assigning homework, while only $39 \%$ of the students reported receiving it!). Even with this discrepancy, both instructors and students seem to feel that homework, whether assigned or initiated by the student, can be effectively performed in the PCATDs. Since individual students are unable to "practice" on their own in a FTD, this is pussibly an important function for PCATDs. 


\section{Participant Comments Regarding Perceived Effectiveness}

In addition to the Likert scale items in the survey, the following open-ended item was included: "Comments regarding the effectiveness of the PCATDs for instrument training", with several blank lines provided for participant response. Table 5 contains the actual comments made by survey participants, divided into positive, neutral, and negative responses. Of the nine instructors who responded to this question, there was one negative and one neutral comment, while the other seven comments were positive.
Five of the nine indicated specifically in their comments that the PCATDs were most effective for introductory lessons. Of the student participants, there were three negative responses, four neutral responses, and thirteen positive responses. As with the flight instructor participants, a number of student participants also indicated that the PCATDs were most beneficial when used for introductory lessons. This finding supports the conclusions drawn

from the survey data. 


\section{Table 5}

Instructors ( 9 of 12 commented):

Negative

"I feel they are not that effective"

Neutral

"Only time I thought PCATD was a good learning tool was intro to holding patterns"

Positive

"Somewhat beneficial for introductory lessons"

"I think they are very useful"

"It is a really good way for students to practice with no cost"

"Less time when used"

"It provides a good introduction with an instructor, but should be utilized more by students for their own practice"

"I think they are effective for intro lessons so the students don't have to deal with the FTD pitch sensitivity"

"For the holds and approaches I found the PCATDs a good way to introduce the maneuvers. For the BAI maneuvers the PCATDs were not as good, as I could not fail instruments at the exact moment I wanted them to fail"

\section{Students ( 20 out of 58 commented)}

\section{Negative}

"Dual lessons are useless in those things. The only thing they are good for is going to practice on your own time"

"It would be easier to be introduced in the FTD"

"PCATDs are not very effective. They are only good while doing holds"

Neutral

"They are effective for navigation and approach type work, but with basic attitude, not so much"

"I feel it helps to get a general idea about approaches and holds, but it doesn't necessarily help a tremendous amount"

"I think that they are overused. They are ok for some intro lessons but there is too much of it in the curriculum"

"The PCATDs are very useful for practice by the student but it is unnecessary to have lessons with an instructor" Positive

"The PCATDs are a good visualization tool for these procedures"

"I feel that the PCATDs are great for an introduction into these parts of flying"

"Overall, I think the PCATDs are useful and effective. They better serve for initial training"

"They were a good introduction to certain concepts to prepare for entering into the Frasca's rather than for extensive training"

"They were good for an introduction to what was going on"

"Helps for basic introduction"

"The PC's are good for introducing new material except for partial panel"

"They are great to be able to visualize what you are doing, so they really help you when introducing something new and for extra practice on your own"

"They helped learning procedures"

"I usually used the PC's to practice holds, since they took me the longest to master. The PC helped me see my mistakes."

"I think they are helpful to introduce topics, especially BAI, but they are decreasingly useful as the flight objectives become more complex"

"The PC sims are extremely boring, but effective in providing a solid foundation to basic instrument theories and procedures."

"The PC sim was pretty effective" 


\section{Conclusions}

Both flight instructors and flight students active in the Parks College instrument curriculum indicated that, based on their experience, some aspects of instrument training could be effectively conducted in PCATDs. The types of lessons that are perceived to be most effective are those that are introductory in nature, particularly introduction to holding patterns, holding pattern entries, and instrument approaches. Basic attitude instrument instruction in PCATDs was seen as less effective, as was continued practice in holding patterns after the introductory lessons.

In addition, hómework assignments conducted in PCATDs, whether instructor or student initiated, were perceived to be effective in improving performance on the elements practiced. From a qualitative analysis standpoint, there were more comments that were positive in nature regarding the effectiveness of the PCATDs than there were negative statements. This was true for both students and flight instruction staff. This finding supports the survey data indicating that both groups of respondents feel that PCATDs can be effective for specific elements of instrument training.

\section{Limitations}

The findings of this study are limited in that only a small and specific population, Parks College students, was surveyed regarding a specific PCATD, the Jeppesen
FS-200. The conclusions drawn from this analysis may or may not hold true for a larger, more diverse group or for a different PCATD. In addition, since this was a qualitative study, it was necessarily limited by the memory, understanding, and overall attitudes of the subjects which participated. For future studies of this type, it may be useful to try to define "effectiveness" more clearly for the participants.

Research into the effectiveness of PCATDs, both from a transfer of training analysis perspective and from a user perspective, needs to continue. This study has attempted to evaluate the attitudes of the users of PCATDs as an important component of the overall picture, but is certainly not a replacement for continued research into transfer of training issues. Continued and expanded research in both arenas will allow identification of the optimal role for PCATDs to play in instrument flight training. Whether they are most valuable for introducing initial skills, for providing an avenue for students to practice emerging skills on their own, or perhaps even as a method of maintaining instrument currency has yet to be resolved. Only with continued probing of the correct role of these devices will the industry be able to utilize PCATDs to their fullest potential. Given the cost advantage and ease of student access to PCATDs versus traditional FTDs, it seems clear that PCATDs are here to stay. The challenge to the training community is to correctly identify the optimal use of these devices.t

Wendy S. Beckman earned an Ed.D. in Higher Education Administration from Saint Louis University, a M.S. in Engineering Management from the University of Missouri, and a B.S. degree in Industrial Engineering from North Carolina State University. She is an Associate Professor in the Department of Aviation Science at Parks College of Engineering and Aviation at Saint Louis University. She also holds an Airline Transport Pilot certificate and a Flight Instructor certificate with ratings for instrument, single, and multi-engine airplane. 


\section{REFERENCES}

Adams, J.A. (1979). On the evaluation of training devices. Human Factors, 21, 711-720.

Andrews, D.H. (1988). Relationships among simulators, training devices, and learning: A behavioral view. Educational Technology, 28, 48-54.

Baum, D.R. (1981). A framework and topics for empirical research on training simulator effectiveness. Proceedings of the ARI Sponsored Workshop for Behavioral and Social Sciences, Technical Report 547.

Beckman, W.S. (2000). A Comparison of the Effectiveness of PC-Based Aviation Training Devices and Conventional 33.

Flight Training Devices for Instrument Training. Journal of Aviation/Aerospace Education \& Research, 9(2), 27-

Borg, W.R. and Gall, M.D. (1989). Educational Resarch: An Introduction (5 $5^{\text {th }}$ Ed.). New York: Longman.

Butcher, R. (1996). PC's for IFR training. Flight Training, 10, 46.

Crawford, A.M., \& Crawford K.S. (1990). Simulation of operational equipment with a computer-based instructional system: A low cost training technology. Human Factors, 20, 123-128.

Federal Aviation Administration. (1997). Qualification and Approval of Personal Computer-Based Aviation Training Devices. AC No: 61-126. Washington, DC: U.S. Government Printing Office.

Finley, D.L., Rheinlander, F.W., Thompson, E.A., \& Sullivan D.J. (1972). Training effectiveness evaluation of naval training devices. Part I: A study of a carrier air traffic control center training device. Technical Report No. NAVTRAEQUIPCEN 70-C-0258-1. Washington, DC: US Navy.

Gay, L.R. (1992). Educational Research Competencies for Analysis and Application (4 ${ }^{\text {th }}$ Ed.). Englewood Cliffs, NJ: Macmillan.

Hays, R.T (1981). Research issues in the determination of simulator fidelity. Proceedings of the ARI Sponsored Workshop. US ARI for Behavioral and Social Sciences, Technical Report No. 547.

Homan, W.J. \& Williams, K.D. (1997). Effects of PC-Based Pretraining on Pilots' Performance in an Approved FlightTraining Device. Journal of Aviation/Aerospace Education and Research, 7(3), 19-28.

Johnson, S.L. (1981). Effect of training devices on retention and transfer of a procedural task. Human Factors, 23, 257-272.

Johnson, S.D. (1995). Transfer of learning. The Technology Teacher, 54, 33-35.

Kinkade, R.G. \& Wheaton, G.R. (1972). Training device design. In P. Van Cott \& R.G. Kinkade (Eds.), Human Engineering Guide to Equipment Design Washington DC: ARI.

Lahey, G.F., \& Edwards, B.J. (1986). The use of a part-task air intercept trainer in F-16 aircrew training: research results. Proceedings of the Interservice/Industry Training Equipment Conference, USA, 560-564.

Lintern, G. (1992). Flight simulation for the study of skill transfer. Simulation/Games for Learning, 22, 336-350.

Micheli, G.S. (1972). Analysis of the transfer of trainiug, substilution, aud fidelity of simulation training equipment (Report 2, Training Analysis and Evaluation Group). Orlando, FL: US Navy. 
Ortiz, G.A. (1993). Transfer of learning effectiveness: PC-based flight simulation. The Journal of Aviation/Aerospace Education and Research, 3(2), 29-33.

Pope, S. (1997, September 1). Desktop simulators come of age. Aviation International News, 98-99.

Rouse, W.B. (1982). A Mixed-fidelity approach to technical training. Journal of Educational Technology Systems, 11, 2328.

Su, D.L. (1984). A review of the literature on training simulators: Transfer of training and simulator fidelity. Report No. 84-1. Atlanta, GA: Georgia Institute of Technology.

Taylor H.L., Lintern G., Hulin C.L., Talleur D., Emanuel T., \& Phillips S. (1997). Transfer of training effectiveness of personal computer-based aviation training devices. Report No. DOT/FAA/AM-97/11. Springfield, VA: National Technical Information Service.

Thomson, D.R. (1989). Transfer of training from simulators to operational equipment - Are simulators effective? Journal of Educational Technology Systems, 17, 213-218.

Valverde, H.H. (1973). A review of flight simulator transfer of training studies. Human Factors, 23, 510-514. 